\title{
SÍNDROME DE BURNOUT: UMA AVALIAÇÃO COM POLICIAIS CIVIS DE UM MUNICÍPIO DA REGIÃO MÉDIO PARAIÍBA
}

\author{
SÍNDROME DE BURNOUT: UNA EVALUACIÓN CON POLÍTICAS CIVILES DE UN \\ MUNICIPIO DEL CENTRO DE LA REGIÓN MEDIA DE PARAÍBA
}

\section{BURNOUT SYNDROME: AN EVALUATION WITH CIVIL POLICE OFFICERS OF A MUNICIPALITY IN THE MEDIUM PARAÍBA REGION}

\author{
Larissa Pinheiro de CASTRO ${ }^{1}$ \\ Carolina de Souza CARVALHO ${ }^{2}$ \\ Eduardo de Freitas MIRANDA ${ }^{3}$
}

RESUMO: O presente artigo busca identificar a ocorrência da Síndrome de Burnout em policiais civis, a partir de um estudo descritivo-quantitativo, realizado com 28 profissionais de uma delegacia de polícia da Região Médio Paraíba. Na coleta de dados, foi utilizado o Maslach Burnout Inventory (MBI) com questões de dados sociodemográficos e profissionais. Como referência para correção foi utilizado os pontos de corte do MBI desenvolvidos pelo Grupo de Estudos e Pesquisas Sobre Estresse e Síndrome de Burnout (GEPEB). Houve predominância de policiais do sexo masculino, casados e com filhos, com graduação em nível superior, ocupantes do cargo de inspetor de polícia. Constatou-se o indicativo de presença da Síndrome em $50 \%$ dos profissionais pesquisados e alto nível nas dimensões de Exaustão Emocional, Despersonalização e Baixa Realização Profissional. Conclui-se a necessidade de um olhar no que tange a saúde mental, com estratégias de cuidado que visem garantir a integridade física e emocional dos policiais.

PALAVRAS-CHAVE: Síndrome de Burnout. Polícia civil. Saúde do trabalhador.

RESUMEN: Este artículo busca identificar la ocurrencia del Síndrome de Burnout en policías civiles, a partir de un estudio descriptivo-cuantitativo, realizado con 28 profesionales de una comisaría de policía de la Región Media de Paraíba. En la recolección de datos se utilizó el Maslach Burnout Inventory (MBI) con cuestiones de datos sociodemográficos y profesionales. Como referencia para la corrección se utilizaron los puntos de corte del MBI desarrollados por el Grupo de Estudio e Investigación sobre el Estrés y Síndrome de Burnout (GEPEB). Predominó el sexo masculino, casados y con hijos, diplomados en la enseñanza superior, ocupando el cargo de inspector de policía. La presencia del Síndrome se encontró en el 50\% de los profesionales investigados y alto nivel

\footnotetext{
${ }^{1}$ Centro Universitário de Barra Mansa (UBM), Barra Mansa - RJ - Brasil. Graduada no curso de Psicologia. ORCID: https://orcid.org/0000-0002-2597-2952. E-mail: larispinheiro25@gmail.com

2 Centro Universitário de Barra Mansa (UBM), Barra Mansa - RJ - Brasil. Graduada no curso de Psicologia. ORCID: https://orcid.org/0000-0001-7824-787X. E-mail: carolinasouzacarvalho@hotmail.com

${ }^{3}$ Universidade Federal Rural do Rio de Janeiro (UFRRJ), Seropédica - RJ - Brasil. Doutorando no Programa de Pós-Graduação em Psicologia. ORCID: https://orcid.org/0000-0003-0570-3277. E-mail: eduardo.ludus@gmail.com
} 
en las dimensiones de Agotamiento Emocional, Despersonalización y Bajo Rendimiento Profesional. Se concluye la necesidad de una mirada hacia la salud mental, con estrategias de atención que tengan como objetivo garantizar la integridad fisica y emocional de los policias.

PALABRASCLAVE: Síndrome de Burnout. Policía civil. Salud del trabajador.

ABSTRACT: This paper seeks to identify the occurrence of Burnout Syndrome in civilian police officers, based on a descriptive-quantitative study conducted with 28 professionals from a police station in the Medium Paraiba Region. Maslach Burnout Inventory (MBI) was used for data collection with socio-demographic and professional data questions. The cutoff points of the MBI developed by the Study and Research Group on Stress and Burnout Syndrome (GEPEB) were used as reference for correction. There was a predominance of male police officers, married and with children, graduated at a higher level, occupying the position of police inspector. The presence of the syndrome was found in $50 \%$ of the professionals researched and high level in the dimensions of Emotional Exhaustion, Depersonalization and Low Professional Achievement. It was concluded that there is a need to look at mental health, with care strategies aimed at ensuring the physical and emotional integrity of police officers.

KEYWORDS: Burnout syndrome. Civil police. Worker's health.

\section{Introdução}

O trabalho sempre esteve presente na vida do homem, podendo este ser fonte de sucessos e alegrias como também de insatisfação e fracasso em várias esferas, mas, segundo Dejours (2015), nem sempre o trabalho possibilita realização profissional. Com o desenvolvimento tecnológico e científico, a globalização tomou grande força, e a dimensão do trabalho concreto passou a dar espaço maior para a do trabalho abstrato, em que se exige além da força "braçal", exige também o intelectual do trabalhador, seu tempo, sua qualificação. Isso significa que as novas exigências do mundo contemporâneo colocam o trabalhador em uma situação em que o trabalho real exige uma atividade além do que está prescrito.

As profissões que exigem contato direto com o público são consideradas as que estão mais expostas a diversos estressores psicossociais relacionados à natureza do trabalho e a do contexto institucional e social a qual estão sujeitas. Isso faz com que essas pessoas estejam vulneráveis a doenças oportunistas como a Síndrome de Burnout, que se mostra como um grave problema no mundo profissional, pois interfere nos níveis institucional, social e também pessoal. 
A Síndrome de Burnout é uma doença que está associada ao mundo do trabalho e que atualmente, seguindo a classificação do CID-10 (10 Código Internacional de Doenças) é conceituada como resultante do estresse crônico que não foi gerenciado com sucesso.

No caso da profissão policial, a qual se trata este estudo, é uma carreira submetida ao setor público, em que exige contato interpessoal direto com a população, e a demanda do trabalho está ligada diretamente a atender os anseios dos usuários. Os agentes policiais tendem a lidar tanto com as pressões da sociedade, que cobram e exigem medidas e políticas mais eficazes na segurança pública, como também a sobrecarga física e emocional geradas justamente pela dificuldade de respostas a estas demandas, prejudicadas pelas condições de trabalho precárias em que vivem.

Isso significa que a capacidade de resposta diminuída faz com que, muitas vezes, o agente utilize recursos próprios para conseguir amenizar essas situações. Nesse sentido, o objetivo desta pesquisa foi o de avaliar a presença da Síndrome de Burnout em Policiais Civis em um município da Região Médio Paraíba e os fatores envolvidos que podem influenciar em seu desenvolvimento, a partir da elucidação das características e dimensões dessa síndrome.

\section{Desenvolvimento}

\section{Histórico e caracterização da Síndrome de Burnout}

Foi em 1974 que o termo Burnout apareceu pela primeira vez, mencionado pelo psiquiatra e psicanalista Freudenberger, a etiologia da síndrome destaca como causas principais aspectos individuais, sendo que a visão do fenômeno estaria mais circunscrita à Exaustão Emocional. Ele propõe uma visão unidimensional da síndrome, não incluindo outros elementos relacionados trazidos.

O primeiro livro sobre o tema traduzido para o português e comercializado no Brasil, foi a tradução de uma obra de Maslach e Leiter em 1999. A psicóloga Social Christina Maslach iniciou estudos adotando uma perspectiva psicossocial com profissionais da área de serviços humanos, diferente da proposta inicial de Freudenberg. Através de seus estudos, o fator psicossocial da Síndrome passou a ser considerado mundialmente como o mais preciso, por ser uma abordagem que leva em consideração o comportamento do indivíduo dentro de um campo social em que por ele sofre influência, mas que também interage e o transforma.

Atualmente, a definição mais aceita e difundida no meio científico internacional sobre Burnout, segundo Cardoso et al. (2017) é a proposta por Maslach e colaboradores que definem a Síndrome de Burnout como "um fenômeno psicossocial que ocorre como resposta 
crônica aos estressores interpessoais advindos da situação laboral”, uma vez que o ambiente de trabalho e sua organização podem ser responsáveis pelo sofrimento e desgaste que acometem os trabalhadores.

Magalhães et al. (2015) dá destaque a seis fontes principais do ambiente laboral que contribuem para a Síndrome de Burnout, são eles: o excesso de trabalho, a falta de controle nos processos, a remuneração insuficiente, a falta de equidade, o colapso na união e os conflitos de valores. Os autores pontuam também que a resposta do sujeito aos fatores de estresse ocupacional, na Síndrome de Burnout estaria composta por três dimensões, que são: a Exaustão Emocional, a Despersonalização e a falta de Realização Pessoal.

A Exaustão Emocional se refere às sensações de esforço físico e emocional que resulta do contínuo relacionamento que os trabalhadores mantêm e devem manter com o público usuário e entre eles mesmos. Este fator se caracteriza pela pessoa perceber que não possui mais condições, recursos e energia que o seu trabalho exige.

A Despersonalização supõe o desenvolvimento de atitudes cínicas e insensíveis diante das pessoas a quem os trabalhadores prestam serviços e até com seus colegas. Este fator é importante, pois diferencia a Síndrome do estresse. Ele cria barreira para não permitir a influência dos problemas dos outros sobre sua vida, age indiferentemente as coisas que acontecem.

A terceira dimensão, diz respeito à baixa Realização Profissional, que é a perda de confiança na realização pessoal e a presença de um autoconceito negativo, atitudes destrutivas em relação a si mesmo, que comumente vem acompanhada de sentimentos de baixa autoestima e incompetência em relação à profissão ou trabalho.

Segundo Silva (2019), o Ministério da Saúde passou a incluir o fenômeno no conjunto de doenças relacionadas ao trabalho em 2001, quando definiu a Síndrome como:

A sensação de estar acabado, ou Síndrome do Esgotamento Profissional, é um tipo de resposta prolongada a estressores emocionais e interpessoais crônicos no trabalho. Tem sido descrita como resultante de uma vivência profissional em um contexto de relações sociais complexas, envolvendo a representação que a pessoa tem de si e dos outros. O trabalhador, que antes era muito envolvido afetivamente com seus clientes, com seus pacientes ou com seu trabalho em si, desgasta-se e, em um dado momento, desiste, perde a energia ou se "queima" completamente. $\mathrm{O}$ trabalhador perde o sentido de sua relação com o trabalho, desinteressa-se e qualquer esforço the parece inútil (Ministério da Saúde do Brasil, 2002 apud SILVA, 2019).

Atualmente, encontra-se registrada no CID 10 (Classificação Estatística Internacional de Doenças e Problemas Relacionados à Saúde) o código Z73.0 e está especificamente 
relacionada ao contexto laboral, reconhecida como uma doença causada pela organização e condições do trabalho. Pode ser avaliada por meio de escalas aplicadas aos funcionários. Atualmente, a mais conhecida é o Maslach Burnout Inventary - MBI, que avaliam estes três fatores citados anteriormente. Ascari et al. (2016) referem que o modelo conceitual da Síndrome de Burnout, apresenta problemas de delimitação, devido à similaridade dos sintomas com outras psicopatologias, tais como: depressão, ansiedade, neurose existencial e desencanto. A sintomatologia do Burnout se deve pelo fato do organismo criar bloqueios e defesas contrários aos fatores estressores do trabalho, resultando em respostas comportamentais alteradas. Por isso, comorbidades podem acompanhá-la, desencadeando problemas de hipertensão, cardiovasculares, diabetes e outras.

\section{A profissão do policial}

A Constituição de 1988 nos garante a segurança pública como dever do Estado, direito e responsabilidade de todos. Embora seu conceito seja muito mais complexo do que o de policiamento, a segurança é transformada em mandato à instituição policial, de tal forma que a produção e a manutenção da ordem constituem a essência de sua missão e de seu processo de trabalho.

A polícia brasileira tem seu início em 1530, a partir de uma solicitação de D. João VI, que tinha como objetivo a administração, promoção da justiça e organização do serviço público. Hoje, é uma carreira do serviço público e sua área de atuação está delimitada e também subordinada aos governos dos estados. Cada estado da federação tem autonomia para organizar a sua polícia civil e também é o responsável pela sua manutenção. A responsabilidade da polícia civil é a de apuração das infrações penais, em que vai exercer uma função de natureza investigativa, cuja atividade é voltada para a atuação repressiva, ou seja, após o acontecimento dos crimes.

No estado de Rio de Janeiro, atualmente está em vigor a Lei 7729/17 que altera o anexo I da Lei 3.586/01 quanto aos cargos efetivos da Polícia civil, estabelecendo assim um quantitativo de 23.386 cargos para o quadro da polícia civil.

Porém, a realidade de policiais em exercício da atividade é bem inferior ao número de cargos descritos na lei, de acordo com os dados disponibilizados no site da Polícia Civil do Estado do Rio de Janeiro, no mês de março de 2019 um total de 8.967 policiais civis estavam em atividade, com um total de 74.162 registros de ocorrências realizados, 3.430 prisões 
efetivadas e 6.456 inquéritos relatados. A partir destes números, observa-se existência de uma demanda exacerbada de ocorrências e prisões e poucos profissionais atuantes na polícia.

O avanço da criminalidade em torno do dinheiro é muito maior que o dos investimentos na Polícia. Essa diferença acaba gerando uma defasagem entre a estrutura física e tecnológica nos dois lados. A consequência é que a segurança pública, como não tem condições físicas e tecnológicas suficientes, não conseguem reprimir a criminalidade. Isto gera na população uma imagem do policial "corrupto" e injusto pela não resolução das infrações.

No Brasil, a classe policial é alvo de descrédito, e, uma grande parte da população, observa essa profissão com desconfiança, e estando em contato direto com a população acaba constantemente sendo julgada por ela, já que a polícia tem o papel proteger e apurar os crimes contra os cidadãos. Segundo Oliveira e Faiman (2019), diversas opiniões são formadas, às vezes positivas, vendo-se o profissional como uma figura de autoridade e respeito, às vezes negativas, quando ele é associado à Ditadura Militar e ao poder abusivo.

Porém, se por um lado o policial tem como responsabilidade a promoção da segurança pública e a repressão da criminalidade, é importante olhar para o policial como um trabalhador, e para atividade policial como um trabalho, e não esquecer-se que este é um servidor público dotado de direitos, inclusive à segurança pessoal como todos os trabalhadores protegidos pela Constituição Federal. Porém, a literatura para esse setor é muito escassa, é nítida a falta de atenção à saúde desse público, que tem raízes históricas profundas desde sua origem na efetivação da força repressora do Estado.

\section{Impacto do Burnout no policial civil}

É evidente a carência de pesquisas especificamente para a Polícia Civil, a maioria dos trabalhos disponíveis na comunidade científica contemplam os Policiais Militares. Embora sejam categorias das profissões da área de Segurança Pública, elas possuem suas peculiaridades no que diz respeito à organização e condições de trabalho.

Os agentes acabam evitando a exposição vinculada ao seu trabalho, pois estão sujeitos a retaliações por parte da sociedade, já que suas exigências podem lhe acarretar uma sobrecarga física e emocional frente às demandas que ele encontra-se incapaz de corresponder; essa evitação também ocorre porque "Sentir que a atividade profissional expõe a riscos sem que sejam tomadas atitudes de proteção pode originar sentimentos de menos 
valia, de humilhação, em forma de vivência depressiva, ou de raiva" (OLIVEIRA; FAIMAN, 2019).

Isso se torna um campo fértil para que se instale a Síndrome de Burnout, que muitas vezes não é reconhecida pelos profissionais, podendo levá-los também a atitudes destrutivas a si mesmo, como suicídio ou inclusive às pessoas que convive e a população, pelo fácil acesso que possui a armas de fogo, cometer agressões ou homicídio. O abuso de álcool e substâncias psicoativas também podem ser usados como estratégias de enfrentamento ou fuga do estresse pelos policiais.

Segundo Dejours (2015), quando a organização do trabalho entra em conflito com o funcionamento psíquico dos sujeitos, eles criam "estratégias defensivas para se proteger". Afetado pelo Burnout, o agente tem a tendência a abandonar o trabalho ou a profissão, devido ao sofrimento psíquico que este lhe causa. Muitos sintomas são agravados porque o funcionário não tem estratégias de enfrentamento dos sentimentos e pensamentos que lhe causam o absenteísmo, ou então, faz o contrário, faltam sem ou criam motivos, prolonga os horários de descanso durante a jornada, evita falar sobre assuntos referentes a ele, como festas e as pessoas. Assim, ele acaba realizando apenas tarefas menos complexas.

Todos esses fatores deixam o agente policial exposto a desenvolver problemas físicos e mentais, pela intensidade e a cronicidade desses eventos e outros citados anteriormente. Dejours (2015) faz uma distinção entre o adoecimento do corpo e o sofrimento mental na psicopatologia do trabalho, em que o adoecimento do corpo toma como base as condições de trabalho (que seria o ambiente físico, ambiente químico, ambiente biológico, condições de higiene, segurança e características antropométricas do posto de trabalho); ao sofrimento mental, ele resulta da organização do trabalho, (designado como a divisão do trabalho, o conteúdo da tarefa, o sistema hierárquico, as modalidades de comando, as relações de poder, as questões de responsabilidade, etc.).

Além dos fatores do ambiente de trabalho é possível encontrar na literatura associações de variáveis demográficas relacionadas à Síndrome de Burnout. Variáveis como Estado civil, escolaridade, filhos, são apontados como fatores que podem ser predisponentes ao Burnout.

\section{Objetivos e métodos de pesquisa}

O presente estudo teve como objetivo avaliar uma equipe de policiais civis lotados em uma Delegacia Policial no interior do Estado do Rio de Janeiro, a presença da Síndrome de 
Burnout, bem como identificar sua relação com as variáveis e os fatores de risco, dessa forma, apresentando as consequências que podem acometer os sujeitos em seu nível de funcionamento e produtividade individual e também nas relações entre pessoas do convívio social e os próprios colegas de trabalho. Participaram do estudo 28 servidores, durante o período de junho a julho de 2019, após a sua aprovação no Comitê de Ética em Pesquisa (CEP) do Centro Universitário de Barra Mansa - UBM/RJ, sob parecer CEP/ UBM 3.390.576 de 13 de Junho de 2019.

A metodologia adotada para realização do estudo desta pesquisa teve caráter exploratório e descritivo de abordagem quantitativa. Para realização da pesquisa, utilizou-se um questionário autoaplicável a todos os funcionários em que foram coletados dados sociodemográficos e profissionais para elucidação do perfil dos participantes e também, 22 questões traduzidas e adaptadas do Inventário de Burnout de Maslach (MBI), validado em suas características psicométricas no Brasil por Benevides-Pereira (2001) e também por outros pesquisadores como Tamayo (1997), Carlotto e Câmara (2004), Trigo (2010) e Schuster et al. (2015).

As questões do questionário encontram-se agrupados de acordo com as três dimensões estabelecidas pelo Modelo Teórico de Maslach: Exaustão Emocional (EE), Realização Profissional (RP) e Despersonalização (DE). Foi utilizado como referência para correção os pontos de corte do MBI desenvolvidos pelo Núcleo de Estudos Avançados sobre a Síndrome de Burnout (NEPASB) - Atualmente chamado de Grupo de Estudos e Pesquisas Sobre Estresse e Síndrome de Burnout (GEPEB) relacionados na Figura 1.

Figura 1 - Tabela de valores de referência para correção do MBI

\begin{tabular}{l|ccc}
\hline \multirow{2}{*}{\multicolumn{1}{c|}{ DIMENSÕES }} & \multicolumn{3}{|c}{ PONTOS DE CORTE } \\
\cline { 2 - 4 } & Baixo & Médio & Alto \\
Exaustão Emocional (EE) & $0-15$ & $16-25$ & $26-54$ \\
Despersonalização (DE) & $0-2$ & $03-08$ & $09-30$ \\
Realização Profissional (RP) & $43-48$ & $34-42$ & $0-33$ \\
\hline
\end{tabular}

Fonte: Elaborado pelos autores a partir dos pontos de corte de GEPEB (FERREIRA, 2017)

Os resultados, de acordo com os escores de cada dimensão, foram classificados em grupos que indicam presença, tendência ou ausência da Síndrome. Para chegar a esse ponto, seguiu-se a orientação proposta por Ferreira (2017), que considera o sujeito com presença de Burnout quando pelo menos uma das duas dimensões, respectivamente a Exaustão Emocional 
(EE) ou Despersonalização, alcançarem altas pontuações associadas à pontuação baixa na Realização Profissional (RP).

Ressalta-se que, ao contrário das outras duas dimensões, a Realização Profissional possui subescala inversa, ou seja, quanto menor for a pontuação total é que o indicativo de Burnout será alto, como é possível verificar na tabela de referência. Essa dimensão possui valor reverso na avaliação em relação às outras duas por que trata da perspectiva positiva para o profissional. Já o indício de tendência ocorre quando apenas uma das dimensões apresenta ponto de corte alto, ou seja, pelo menos uma apresenta alta tendência associado a uma com índice médio. Qualquer outro resultado encontrado indica ausência da Síndrome. Os dados obtidos foram tabulados e analisados estatisticamente por meio do programa Microsoft Excel®.

\section{Resultados e discussão}

Os participantes da pesquisa, predominantemente ocupam o cargo de Inspetor de Polícia, que corresponde a 16 profissionais (57\%), seguido dos Oficiais de Cartório com 07 profissionais (25\%). Participaram também 03 servidores com a ocupação de Investigador de Polícia (11\%), 01 Comissário de Polícia (4\%) e 01 Delegado de Polícia (4\%).

A partir da análise dos dados sociodemográficos, pode-se observar enquanto perfil dos profissionais atuantes, a prevalência de profissionais do sexo masculino, dos entrevistados, 23 eram homens (82\%) e 05 mulheres (18\%). O que nos leva a refletir que apesar da evolução da participação feminina na polícia, ainda há a associação da atividade policial com a masculinidade e sua virilidade, que segundo Casagrande (2016) nos aponta para uma "reivindicação pela igualdade de gênero além da equidade de cargos/funções assumidos por homens e mulheres policiais, mas a busca constante de ressignificações atribuídas ao "masculino" e ao "feminino" na interface com as relações sociais como um todo"(p.26).

Dos profissionais participantes, 16 relataram serem casados (57\%), 05 solteiros (18\%), 02 possuem um companheiro (7\%), 03 relataram ser divorciados (11\%), 02 não informaram seu estado civil (7\%). No que se refere ao número de filhos, 17 profissionais relataram ter filhos (61\%), 10 profissionais não possuem filhos (36\%), 01 servidor não disponibilizou tal informação.

Apesar de haver controvérsias, há pesquisas que apontam o fator de possuir filhos como um equilibrador afetivo. De acordo com a pesquisa realizada por Rodriguez e Carlotto (2014) os profissionais que possuem filhos apresentam um grau menor de distanciamento e 
indiferença em relação às pessoas, com a associação da maternidade/paternidade à maior responsabilidade e maturidade no manejo com o outro e desenvolvimento de tolerância com os estressores.

No que tange a análise profissional, 18 policiais possuem graduação em nível superior completo (64\%), 06 possuem especialização (21\%), 03 possuem ensino médio completo (11\%), e 01 possui mestrado (4\%). Segundo Fonseca et al. (2017) as pessoas com maior grau de escolaridade são mais propensas ao Burnout em relação às pessoas de menor grau escolar, devido as expectativas e responsabilidades que sua função exige de seus recursos individuais para a realização do trabalho.

Figura 2 - Quadro de percentual de carga horária semanal dos profissionais participantes da pesquisa

\begin{tabular}{|c|c|}
\hline CARGA HORÁRIA SEMANAL & $(\%)$ \\
\hline $32 \mathrm{~h}$ & $14 \%$ \\
\hline $36 \mathrm{~h}$ & $4 \%$ \\
\hline $40 \mathrm{~h}$ & $32 \%$ \\
\hline $44 \mathrm{~h}$ & $7 \%$ \\
\hline $48 \mathrm{~h}$ & $18 \%$ \\
\hline $50 \mathrm{~h}$ & $7 \%$ \\
\hline $54 \mathrm{~h}$ & $4 \%$ \\
\hline Acima De 54h & $14 \%$ \\
\hline $\boldsymbol{P E R I O D O} \boldsymbol{D E} \boldsymbol{T R A B A} \boldsymbol{L H O}(\boldsymbol{D I A S})$ & $\mathbf{(} \%)$ \\
\hline $1-3$ dias & $36 \%$ \\
\hline $4-6$ dias & $57 \%$ \\
\hline 7 - 9 dias & $0 \%$ \\
\hline $10-15$ dias & $4 \%$ \\
\hline Não informado & $4 \%$ \\
\hline &
\end{tabular}

Fonte: Dados da pesquisa, 2019

Outro facilitador da Síndrome de Burnout se relaciona aos turnos de trabalho, a literatura mostra a correlação positiva e significativa entre as horas semanais de trabalho e as 3 dimensões de Burnout. A partir dos dados pesquisados, dispostos na figura 2, pode-se observar que $43 \%$ dos profissionais (12 policiais) têm carga horária semanal que varia de 48 a 54 horas ou mais de trabalho, e a prevalência de um período de trabalho entre 4 a 6 dias por semana referente a $57 \%$ dos profissionais (16 policiais), seguido de $36 \%$ com um período de 1 a 3 dias de trabalho por semana (10 policiais). Dentre os participantes, foi verificado que $29 \%$ dos policiais possuem outro emprego, com carga horária que varia de 8 a 50 horas semanais.

Figura 3 - Quadro de Percentual das últimas férias gozadas pelos profissionais participantes da pesquisa 


\begin{tabular}{|c|c|}
\hline ULTIMAS FÉRIAS & $\mathbf{( \% )}$ \\
\hline 2015 Ou Anterior & $14 \%$ \\
\hline 2016 & $4 \%$ \\
\hline 2017 & $7 \%$ \\
\hline 2018 & $43 \%$ \\
\hline 2019 & $29 \%$ \\
\hline Não Informado & $4 \%$ \\
\hline
\end{tabular}

Fonte: Dados da pesquisa, 2019

Apesar de não haver na literatura correlação aos períodos de férias gozadas com a Síndrome de Burnout, foi observado que apenas 29\% dos profissionais participantes gozaram férias neste ano, conforme apresenta o quadro acima. Jornadas longas de trabalho associadas a sobrecarga de atividades e as condições precárias de trabalho, sem intervalo apropriado para descanso atuam como um fator de risco para a saúde do profissional da polícia (SANTOS, 2019).

Quanto à análise das questões do Inventário de Burnout de Maslach, a partir da soma das pontuações, foi identificado que 46\% (13) dos profissionais participantes apontaram um alto nível de Exaustão Emocional, 64\% (18) um alto índice de Despersonalização, seguido de $61 \%$ (17) de servidores com um alto índice de Baixa Realização Profissional, conforme apresentado a seguir.

Figura 4 - Tabela de descrição do percentual das dimensões do MBI em níveis, a partir dos resultados apresentados pelos profissionais participantes da pesquisa

\begin{tabular}{c|ccc}
\hline \multirow{2}{*}{ DIMENSÕES } & \multicolumn{3}{|c}{ NÍVEIS } \\
\cline { 2 - 4 } & BAIXO & MÉDIO & ALTO \\
Exaustão Emocional & $11 \%$ & $43 \%$ & $46 \%$ \\
Baixa Realização Profissional & $4 \%$ & $36 \%$ & $61 \%$ \\
Despersonalização & $0 \%$ & $36 \%$ & $64 \%$ \\
\hline
\end{tabular}

Fonte: Dados da pesquisa, 2019

Tais resultados chamam a atenção por identificarem altos níveis nas 03 dimensões, apontando o indicativo de presença da Síndrome de Burnout entre os policiais participantes da pesquisa. Ao observar a média de Exaustão Emocional apontada nesse estudo, pode-se relacionar ao trabalho cansativo com jornadas de trabalho longas, turnos de trabalho, as cobranças internas e externas que os policiais recebem, tanto da organização e burocratização do trabalho como da população em geral. 
O pouco tempo para descanso, associado a uma grande carga horária de trabalho, expectativas frustradas quanto a carreira e profissão, baixos salários, contato direto com a violência além de resultarem no estresse e desgaste emocional acabam por levar o sujeito a um endurecimento emocional, a Despersonalização, criando assim uma barreira para não ser influenciado pelos problemas do outro, assumindo uma postura de cinismo e até mesmo hostil com o público.

Baseado nos estudos de Maslach e colaboradores, Cardoso (2017) afirma que a realização profissional, geralmente influenciada pela exaustão emocional e despersonalização, leva o profissional a fazer uma autoavaliação em que tende a perceber diversos aspectos negativos sobre a sua vida profissional, desvalorizando seu trabalho, gerando uma atuação de apenas cumprimento da obrigação, com queda na qualidade do desempenho do trabalho e baixa autoestima.

Figura 5 - Quadro com Indicativo de Presença, Tendência e Ausência da Síndrome de Burnout

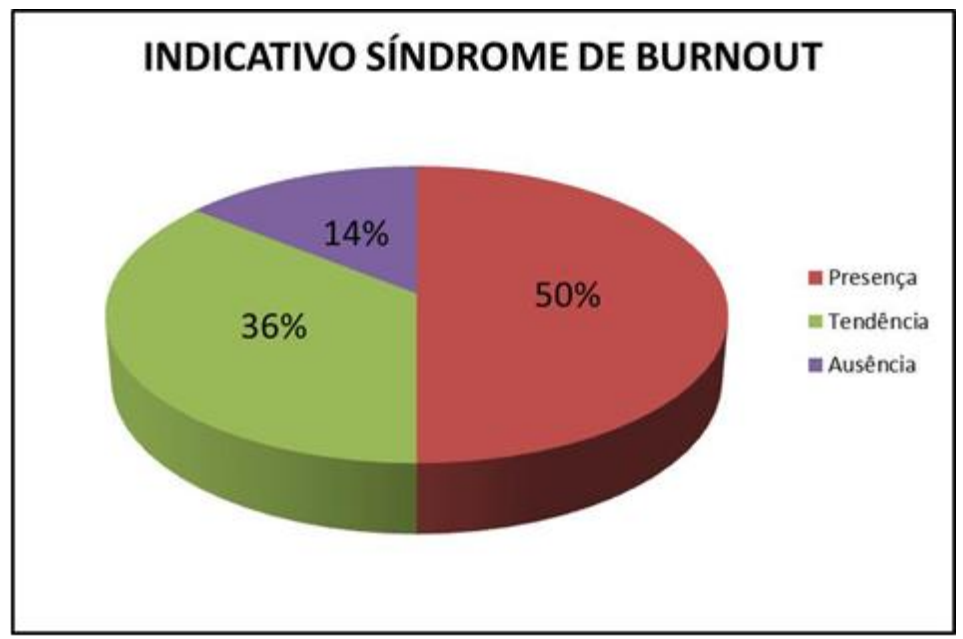

Fonte: Dados da pesquisa, 2019

A partir da somatória das pontuações e uso dos pontos de corte do MBI desenvolvidos pelo GEPEB constatou-se que 50\% (14) dos profissionais apontam um indicativo de presença de Burnout, 36 \% (10) profissionais apresentam indicativo de tendência a Síndrome, e 14\% (04) profissionais apresentaram indicativo de ausência da Síndrome de Burnout.

Como resultados gerais, nessa pesquisa houve a predominância do sexo masculino, casados, em sua maioria com filhos, ocupantes do cargo de inspetor de polícia. A partir dos dados levantados pelo MBI em comparação aos dados relacionados à jornada de trabalho dos profissionais participantes, temos $43 \%$ dos profissionais atuando com carga horária acima de 44 horas semanais e 57\% com um período de trabalho de 4 a 6 dias seguidos que contribuem 
para essa alta presença da síndrome e que corrobora com a correlação proposta na literatura entre as horas semanais de trabalho e a sintomatologia do Burnout.

Levando em consideração a data da realização da pesquisa, $68 \%$ dos profissionais participantes ainda não haviam gozado férias neste ano de 2019. Tendo em vista a jornada de trabalho, longos períodos sem férias, além de $29 \%$ dos profissionais que possuem outro emprego, observa-se uma sobrecarga de trabalho em grande escala, que acaba levando o profissional a desenvolver sua atividade com baixo rendimento e favorecendo o desencadear de altos índices de Exaustão Emocional, além de atuar como um preditor positivo e significativo da Despersonalização.

Outro fator a ser pontuado é a escolaridade, em concordância com a literatura, que aponta o nível de escolaridade à Síndrome de Burnout, 64\% dos profissionais pesquisados possuem nível superior completo e $21 \%$ possuem alguma especialização. A escolaridade pode servir como um desestimulador aos profissionais por não ser valorizada na progressão de carreira, podendo contribuir para os altos índices de baixa Realização Profissional. Nos estudos de Boechat e Ferreira (2014) a escolaridade foi identificada como um fator com relação significativa a Realização Profissional.

A partir dos resultados apresentados, pode-se afirmar que o policial civil sofre um desgaste no desenvolvimento de sua atividade laboral de diferentes impactos e intensidades que merecem atenção e cuidado no gerenciamento do estresse. Em uma pesquisa realizada por Silva et al. (2018) sobre a Síndrome de Burnout entre policiais civis, foi constatado que em média os policiais "se sentem esgotados emocionalmente devido ao seu trabalho", confirmando a necessidade de um olhar de cuidado para esses profissionais que atuam entre o perigo e o medo na repressão da criminalidade, necessitando de vigilância constante no exercício da atividade contra a violência e o crime e não se expor a riscos.

\section{Considerações finais}

A profisssão do policial é considerada estressante, por ser uma atividade desenvolvida no meio conflitivo de marginalidade e criminalidade, além de ter como ferramenta de trabalho a arma de fogo, que por si só possui um risco e caracteriza como um fator de estresse (RIBEIRO, 2015). Além desses prejuízos, os policiais precisam lidar com os reflexos negativos do trabalho policial perante a sociedade, as condições precárias de trabalho, jornadas excessivas, que causam prejuízo para suas atividades e consequentemente prejuízo em sua saúde psíquica e física. 
O adoecimento do policial precisa de uma atenção das áreas de saúde mental, considerando a complexidade da relação entre saúde $\mathrm{x}$ trabalho $\mathrm{x}$ doença, que têm impacto significativo na segurança pública e em outras esferas, como na economia, cultura, saúde e outros. Por isso, identificar precocemente as situações estressoras possibilita o encontrar formas de enfrentamento e de modificação das condições e da organização do trabalho que causa o sofrimento, e assim, diminuir o risco de adoecimento dos policiais pela Síndrome de Burnout.

É evidente a carência de pesquisas especificamente a esse público-alvo apesar da profissão do policial ter características específicas que podem contribuir para o adoecimento. Encerrando essa reflexão chama-se a atenção para a produção de estudos e propostas de ação efetivas para minimizar a vulnerabilidade desses profissionais, tanto na modernização e melhoria nos processos de trabalho como na promoção do cuidado com a saúde e qualidade de vida desse trabalhador evitando o adoecimento.

Esta pesquisa desperta a necessidade de discussão a respeito das jornadas e carga horária de trabalho prolongadas em que os profissionais da polícia civil estão submetidos, bem como na importância de abertura de ofertas de serviços de prevenção, diagnóstico e tratamento aos profissionais que atuam em uma atividade de característica perigosa e que seu adoecimento impacta diretamente na sua atuação profissional, desde o atendimento ao público, sendo mais ríspido e hostil, até mesmo colocando em situações de risco a si mesmo e os outros.

O cansaço físico associado ao desequilíbrio emocional pode levar esses profissionais à ineficácia no desempenho do exercício profissional assumindo atitudes de riscos e expondo não só a si, mas a população em geral a perigos em potencial.

\section{REFERÊNCIAS}

ASCARI, R. A.; DUMKE, M.; DACOL, P. M.; MAUS, S.; SÁ, C. A.; LAUERT, L. Prevalência de Risco para Síndrome de Burnout em Policiais Militares. Cogitare Enferm, v. 21, n. 2, p. 01-10, 2016. Disponível em:

https://revistas.ufpr.br/cogitare/article/view/44610/28562. Acesso em: 21 jul. 2020.

BOECHAT, M. A. M.; FERREIRA, M. C. Preditores Individuais e Organizacionais do Burnout em Servidores Públicos Federais. Psic., Saúde \& Doenças, Lisboa, v. 15, n. 3, p. 738-750, dez. 2014. Disponível em:

http://www.scielo.mec.pt/scielo.php?script=sci_arttext\&pid=S164500862014000300014\&lng $=$ pt\&nrm=iso. Acesso em: 10 out. 2019. 
CARDOSO, H. F. et al. Síndrome de burnout: análise da literatura nacional entre 2006 e 2015. Rev. Psicol., Organ. Trab., Brasília, v. 17, n. 2, p. 121-128, jun. 2017. Disponível em: http://pepsic.bvsalud.org/pdf/rpot/v17n2/v17n2a07.pdf. Acesso em: 10 jul. 2019.

CASAGRANDE, M. A. Ser mulher na polícia civil: um estudo sobre as delegadas de polícia em formação na Acadepol/Sc em 2016. 2016. Monografia (Especialização em Gênero e Diversidade na Escola) - Universidade Federal de Santa Catarina, Florianópolis, 2016. Disponível em: https://repositorio.ufsc.br/xmlui/handle/123456789/173771. Acesso em: 21 jul. 2020.

DEJOURS, C. A loucura do trabalho: estudo de psicopatologia do trabalho. 6. ed. São Paulo: Cortez, 2015.

FERREIRA, J. S. Burnout em profissionais de enfermagem atuantes na atenção básica de saúde. 2017. 87 f. Dissertação (Mestrado em Enfermagem) -Universidade Federal do Estado do Rio de Janeiro, Rio de Janeiro, 2017. Disponível em:

http://www.unirio.br/ppgenf/dissertacoes/dissertacoes-ppgenf-unirio-ano-2017/dissertacaojessica-ferreira-do-nascimento. Acesso em: 21 jul. 2020.

FONSECA, S.; QUEIRÓS, C.; GUIMARÃES, F.; MARTINS, V. Risco de burnout e trauma em profissionais da ferrovia com e sem experiência em acidentes. Territorium, n. 25, p. 113127, 2017. Disponível em: https://impactum-journals.uc.pt/territorium/article/view/16477723_25-1_9. Acesso em: 21 jul. 2020.

MAGALHÃES, E.; OLIVEIRA Á. C. M. S.; GOVÊIA C. S.; LADEIRA, L. C. A.; QUEIROZ, D. M.; VIEIRA, C. V. Prevalência de síndrome de burnout entre os anestesiologistas do Distrito Federal. Rev. Bras. Anestesiol, v. 66, n. 2, 2015. Disponível em: $<$ http://dx.doi.org/10.1016/j.bjane.2013.07.016. Acesso em: 10 set. 2019.

OLIVEIRA, T. S.; FAIMAN, C. J. S. Ser policial militar: reflexos na vida pessoal e nos relacionamentos. Rev. Psicol., Organ. Trab., Brasília, v. 19, n. 2, p. 607-615, jun. 2019. Disponível em: http://pepsic.bvsalud.org/scielo.php?script=sci_arttext\&pid=S198466572019 000200005\&lng=pt\&nrm=iso. Acesso em: 21 jul. 2020.

RIBEIRO, W. L. M. Impacto do trabalho policial na qualidade de vida dos investigadores da polícia judiciária civil de Mato Grosso. 2015. Monografia (Especialização em Políticas de Segurança Pública e Direitos Humanos) - Universidade Federal de Mato Grosso, Cuiabá MT, 2015. Disponível em: https://bdm.ufmt.br/handle/1/20. Acesso em: 21 jul. 2020.

RIO DE JANEIRO. Lei Estadual n. 7729, de 09 de outubro de 2017. Dispõe sobre a reestruturação do quadro permanente da polícia civil do estado do rio de janeiro e dá outras providências. Disponível em: https://gov-rj.jusbrasil.com.br/legislacao/508414171/lei-772917-rio-de-janeiro-rj. Acesso em: 15 set. 2019.

RODRIGUEZ, S. Y. S.; CARLOTTO, M. S. Prevalência e fatores associados à síndrome de burnout em psicólogos. Ciencia e Trabalho, v. 16, n. 51, p. 170-176. 2014. Disponível em: https://scielo.conicyt.cl/pdf/cyt/v16n51/art08.pdf. Acesso em: 21 jul. 2020. 
SANTOS, A. R. Transtorno de Estresse em Policiais: Índice de Crimes Relacionados à Saúde Física e Mental, com um Viés à Síndrome de Burnout. 2019. Monografia (Trabalho de Conclusão de Curso de Direito) - Centro Universitário de Maringá, Maringá, 2019. Disponível em: http://rdu.unicesumar.edu.br/handle/123456789/5127. Acesso em: 21 jul. 2020.

SILVA, C. C. S. et al. A síndrome de burnout entre policiais civis. REME rev. min. enferm., v. 22, e-1095, 2018. Disponível em: https://pesquisa.bvsalud.org/portal/resource/pt/biblio905273. Acesso em: 15 set. 2019.

\section{Como referenciar este artigo}

CASTRO, L. P. de; CARVALHO, C. de S.; MIRANDA, E. de F. Síndrome de Burnout: uma avaliação com policiais civis de um município da região Médio Paraíba. Doxa: Rev. Bras. Psico. e Educ., Araraquara, v. 22, n. esp. 1, p. 299-314, out., 2020. e-ISSN: 2594-8385. DOI: https://doi.org/10.30715/doxa.v22iesp.1.14135

Submetido em: 20/04/2020

Revisões requeridas: $15 / 06 / 2020$

Aprovado em: 20/08/2020

Publicado em: 30/09/2020 